\title{
Analysis of Strengthening Variants of Existing Masonry Buildings for Seismic Resistance- Case Studies of Typical Residential Buildings in Niš
}

\author{
Jelena SAVIĆ*, Radomir FOLIĆ, Dragan KOSTIĆ, Veliborka BOGDANOVIĆ, Miomir VASOV
}

\begin{abstract}
The revitalization of existing masonry buildings, built decades ago, is a very topical and complex structural engineering issue, especially when the building was built in the area of significant seismic activity. A large number of masonry buildings in the city of Niš, as well as in other places in Serbia, were built in the period before the adoption of technical regulations on the design and construction of seismically resistant structures and they are at insufficient safety level in the event of an earthquake. Therefore, it is necessary that structural strengthening meets the seismic resistance requirements laid down in Eurocode 8 or other relevant codes. In order to choose the method of structural strengthening, detailed seismic analyses must be carried out in several variants along with the application of relevant technical regulations. The effects of five analyzed structural strengthening methods were checked against the provisions of Eurocode 8, Part 1 and Part 3, which relate to the recommendations for the geometric characteristics of shear walls, and they were applied on two types of existing masonry buildings in Niš. On the basis of the performed analyses, conclusions were drawn regarding the methodological approach of the assessment of the condition of the structure, its seismic resistance and decision-making on remediation and/or strengthening measures.
\end{abstract}

Keywords: Eurocode 8; Existing masonry buildings; seismic strengthening methods and techniques; seismic resistance

\section{INTRODUCTION}

The existing housing stock in Serbia largely consists of masonry buildings. Most of these buildings constructed in an earlier period are characterized by a low level of housing quality, deterioration, damage of the main and supporting structures and a short service life. Depending on the period when they were created, different materials and construction systems were applied. Earthquakes, fires, storm winds and other disasters very often caused damage. When other causes are included, such as the lack of maintenance, excessive and uneven settlement, impact of adjacent structures, then it can be concluded that defining the cause of damage is a very complex process. Earthquakes belong to external factors causing damage to buildings and they cannot be predicted, so for buildings in the mentioned condition the seismic load is a high risk. Depending on the building strength, the damage can range between minor and devastating. Today, modern methods of calculation and principles of a seismic design are studied in detail and in professional practice. However, a large number of existing masonry buildings were built during the period when there were no specific regulations on a seismic design. Thus, it is particularly important to analyze, calculate, and determine their condition and behaviour in the seismic events. It is imperative that such structures now meet the basic requirements for masonry buildings in seismically active areas prescribed by Eurocode 8 [1]. The calculation according to Eurocode 8 is based on two basic requirements for the expected earthquake: the requirement that the structure does not collapse and the requirement of limiting the structural damage. Particularly important for existing buildings is Part 3 [2], which deals with the assessment of the condition of individual buildings in order to decide on the necessary structural interventions and on undertaking the strengthening measures in the event of a seismic action. The status assessment, as stated in FEMA 356 [3], requires an appropriate methodological approach with the implementation of a series of activities that include observations, measurements, calculations and qualitative analysis.
In that sense, the aim of this paper is to present five variant solutions for strengthening masonry buildings, i.e. their load-bearing structures, to explain the way they are chosen and provide a comparative analysis of seismic calculation results, on the basis of which the most optimal solution is proposed. The models for the comparative analysis are built as clearly defined, simple in terms of speed and manner of performance and it is unlikely to arise possible dilemmas in the process of selecting a relevant solution.

The recommendations and provisions of the current Eurocode 8 were used for the assessment of the seismic resistance of the two considered building types. It should be emphasized that in the process of considering the existing buildings within Eurocode 6 and Eurocode 8, their geometry, floor plan layout, number of storeys, types and arrangement of load-bearing walls with all their physical and mechanical characteristics were taken into account, which is very important in analyzing their seismic action response.

The provisions "for simple masonry buildings" were used for a simplified and quick analysis, while the FEDRA software package was employed in the stress quantitative analysis.

\section{LITERATURE REVIEW}

Most of the researchers in this field come from the countries with centuries-long tradition and extensive stock of traditionally built structures. When such buildings are in question, the goal is to preserve the authentic architectonic and visual expression and form. An intervention on the cultural heritage using characteristic, conventional methods was demonstrated by Beckmann and Bowles (2004) [4] in their book "Structural aspect of building conservation". On the other hand there is an increasing number of authors such as Gattesco (2011) [5] oriented to the use of contemporary materials in restoration of historically valuable buildings, while Triantafillou and Fardis (1997) [6] concentrated on the use of composite materials for strengthening masonry buildings. Balkan area 
and beyond is in the zone of increased seismic activities, and thus, rehabilitation of the existing masonry, and residential buildings in general, became the subject of increasingly frequent and extensive research such as: Ademović and Hrasnica (2014) [7], Churilov and DumovaJovanoska (2009) [8] and many others. The papers of Tomaževič (2000) [9], (2014) [10] with the experience from Slovenia refer to the rehabilitation of the existing masonry buildings in seismic areas. All the research by Tomaževič is based on Eurocode 6 (EN 1996:2005) [11] and Eurocode 8 (EN 1998:2005) [1]. In some segments it is referred to the Technical norms for construction of highrise buildings in seismic areas of 1981 [12], which was in force for the area of the West Balkans. His research in the field of the old masonry buildings wall bearing capacity calculation, and the results he published date back to 1978 and 1986. The more recent research in the field of design of seismically resistant buildings in the region can be found in Greece, Croatia and Turkey. Trogrlić and Harapin (2008) [13], within the Professional Development Program in Construction, very concisely presented the basics of calculating masonry buildings, gave recommendations important for a seismic design and provided specific examples from practice, all of which was used extensively in the analysis of the considered buildings presented in this work. In the paper Ozmen (2011) [14], related to the calculation of a masonry, historically important building, in the area of Anatolia in Turkey, and the seismic design of the strengthened structure was performed according to TEC, standing Turkish technical codes.

The needs for improving the quality of housing through the process of revitalization, with an assessment of the condition of old buildings, as well as the need for their maintenance, are the subject of detailed analysis in the works of Stanišić and Kurtović-Folić, (2015) [15] and Kurtović-Folić and Folić, (1986) [16]. From the titles of the works, it can be concluded that a great deal of attention was paid to discovering the causes of the damage, their classifications and the need for constant inspections while creating a maintenance strategy, as it is done by well developed countries. It is very important at the beginning of the strengthening process, to remove the causes of damage and then to repair the structure.

Table 1 Methods of intervention on the walls

\begin{tabular}{|c|c|}
\hline \multirow{8}{*}{ 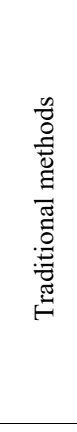 } & Repair of cracks \\
\hline & Repointing the joints with cement mortar \\
\hline & Adding reinforcement \\
\hline & $\begin{array}{l}\text { Application of reinforced cement coating on one or both sides } \\
\text { of the walls }\end{array}$ \\
\hline & Reinforcement of walls with shotcrete \\
\hline & Injecting walls \\
\hline & Prestressing the walls in vertical or horizontal directions \\
\hline & $\begin{array}{l}\text { Reconstruction of the most severely damaged parts of the } \\
\text { walls }\end{array}$ \\
\hline \multirow{4}{*}{ 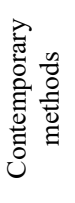 } & Stainless steel hoop system \\
\hline & Wrapping in FRP (Fiber Reinforced Polymer) strips \\
\hline & $\begin{array}{l}\text { Application of strips, rods, nets and fabrics based on FRP } \\
\text { (Fiber Reinforced Polymer) for wall reinforcement }\end{array}$ \\
\hline & Application of mortar reinforced with GFRP mesh \\
\hline
\end{tabular}

Tomažević (1999) provides a comprehensive overview and presentation of constructive measures for repairing and strengthening the masonry structures in his book [17], classifying them into two categories: techniques for repairing and strengthening of individual elements of the masonry structure and techniques for improving the structural integrity. As damage to masonry structures is most often found on walls, intervention methods, according to the extent of damage and the amount of work, can be classified into traditional and modern. The following Tab. 1 provides an overview of the most common methods in practice.

The selection of the most optimal solutions should be based on the acquired knowledge and conclusions about the behaviour of the structure within the conducted static and dynamic analyses, from which follows the required rigidity, resistance and size of deformation of the structure in accordance with the planned purpose and use of the building. Having in mind the specificity and complexity of the works, expensive materials and the application of special technology, it is necessary to consider the problem from the economic aspect as well.

\section{ANALYSIS OF THE OBSERVED EXISTING MASONRY BUILDINGS}

The paper presents an analysis of existing masonry buildings built in the 1960s, in a residential block in Niš. In the observed block, two different types of masonry buildings are represented. Their difference is mostly reflected in the different geometry, that is, the direction and the length of the bearing walls. Given that these structures were constructed in the period prior to the introduction of the Building Regulations in Seismically Active Areas of 1964 [18], it is necessary to carry out controls of their loadbearing capacity and service ability to seismic effects. After the contemporary seismic re-zoning, the site found itself located in the VIII seismic zone, and according to EC 8 the design acceleration of the ground is $0,2 \mathrm{~g}$.
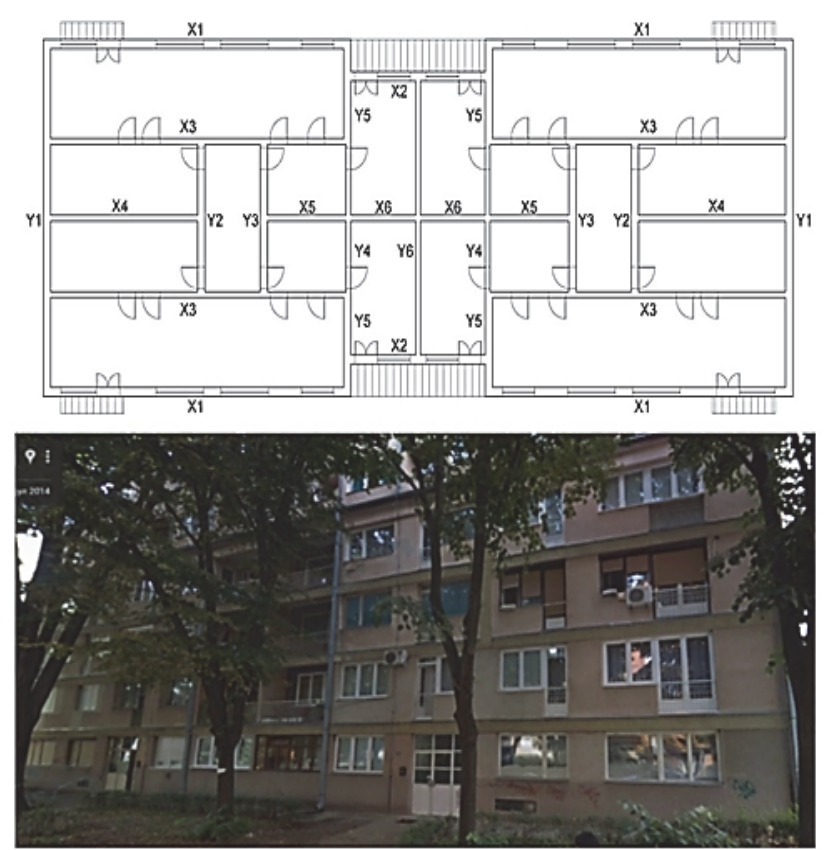

Figure 1 Observed building, "type A" 
The "type A" building is a masonry building with an elongated rectangular layout, with bearing walls extending along the long side of the building ( $x$ direction), thus constituting a longitudinal bearing system, as seen in Fig. 1.

The building has a total of 5 floors including basement, ground floor and three floors. The bearing structure consists of the solid brick walls (M10) bound with lime cement mortar (M2.5) in the basement and ground floor, and with limestone mortar (M1.0), on the I, II and III floor.

Testing the class of the masonry blocks, built in the walls of the building at the observed location was performed by the Building materials laboratory, at the Faculty of Civil Engineering and Architecture of Niš. A more detailed results presentation of the conducted testing will be presented in the chapter 5. As stated by Penava in the paper [19], a more reliable status assessment of the existing building is performed by using the data obtained by testing the built-in materials.

The system of longitudinal bearing walls, $25 \mathrm{~cm}$ and $38 \mathrm{~cm}$ thick, without vertical tie beams is a part of the building, tasked with resisting the vertical load. Transversally installed walls are connecting walls, with a small number of openings, while the longitudinal façade and interior walls of $x$ direction are weakened by a large number of openings for windows and doors.

The "type B" building (Fig. 2), is also a load bearing structure, of an almost square floor plan, 16,97 $\mathrm{m}$ in $x$ and $16,31 \mathrm{~m}$ in $y$ directions. Here, the part of the building structure tasked with resisting the vertical load, is also a system of longitudinal load-bearing walls without vertical tie beams. As with the previous building, the façade walls are weakened by a large number of openings for windows and doors, while the interior ones have significantly fewer openings. Since the building has the ground floor and three floors, the walls on the ground floor are also built with solid brick and lime cement mortar, and the floors with solid brick and lime mortar.

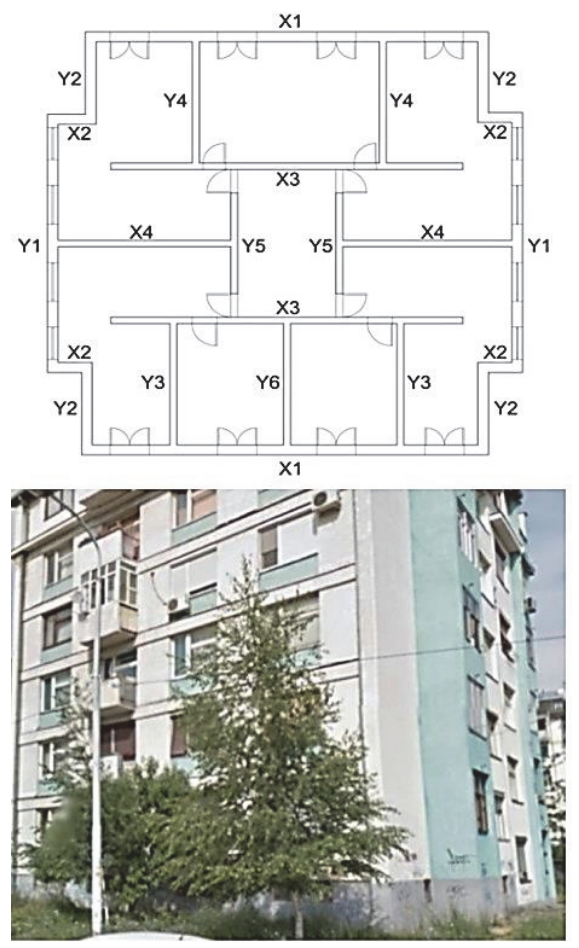

Figure 2 Observed building "type B"
The analysis of the building foundations and their spatial-geometric characteristics reveals a small percentage of walls that extend transversely along the $y$ direction in the "type A" buildings. This can cause the insufficient bearing capacity of the walls to shear load and poor/compromised stability of the building in the case of a seismic action (Tab. 2).

Table 2 Contents of shear walls in the observed buildings

\begin{tabular}{|c|c|c|}
\hline & $\begin{array}{c}\text { Contents of bearing- } \\
\text { shear walls in } \\
x \text { direction }\end{array}$ & $\begin{array}{c}\text { Contents of bearing- } \\
\text { shear walls in } \\
y \text { direction }\end{array}$ \\
\hline "Type A" building & $12,2 \%$ & $6,59 \%$ \\
\hline "Type B" building & $9,1 \%$ & $8,8 \%$ \\
\hline
\end{tabular}

Further structural analysis may indicate the necessity for the construction of new walls in the $y$ direction which will additionally strengthen and stiffen the building structure. In "type B" buildings, the share of the walls for $x$ and $y$ directions is approximately equal, which is more favourable for its stability (Tab. 2). This is an approximate indication of the seismic resistance of masonry buildings, from which a fairly accurate insight into seismic resistance is obtained. For a more accurate estimation of structural load-bearing capacity, the results of static-seismic calculation are used.

\section{CALCULATION METHODS}

For the complete static-seismic analysis of the observed buildings, the software package FEDRA [20] was used, which is intended for the calculation and analysis of masonry structures, based on the finite element method. The FEDRA program is designed to base the calculation of masonry structures on the principles of Eurocode 6 (2005) (EN 1996-1-1:2005), including Eurocode 2 for the calculation and design of concrete elements (tie beams, beams, columns) and Eurocode 5 for the design and calculation of timber structures and roofs that are part of the structural assembly of a building.

When analysing the structure of the building, the FEDRA software first reduces and calculates the vertical load that can be permanent and useful. In this way, the correctness of the built model is also checked, as well as the behaviour of the structure under the vertical loading. The obtained vertical loads form the basis for the calculation of the seismic forces acting on the structure.

The design for the masonry is done for the ultimate limit state based on Eurocode 6 . All the checks for loading cases $1,35 \mathrm{~g}+1,50 \mathrm{q}$, and 1,00 g + 0,30 $\mathrm{q}+$ earthquake, are done for compression and shear. In addition verification of slenderness ratio requirements and checks for strength at stress concentrations are performed according to Eurocode 6. These checks imply [20]:

$N_{\text {sd }}<N_{\text {rd }}$

$N_{\text {rd }}$ - design vertical load resistance, $N_{\text {sd }}$ - vertical design load (EC 6):

$$
N_{\text {rd }}=\frac{\Phi_{i, m} t f_{k}}{\gamma_{M}}
$$


$\Phi_{i, m}$ is the capacity reduction factor, which takes into account the effects of slenderness and eccentricity of the loading; $t$ is the wall thickness; $f_{k}$ is the characteristic compressive strength of the masonry; $\gamma_{M}$ is the partial safety factor for the material.

$V_{\text {sd }}<V_{\text {rd }}$

$V_{\text {sd }}$ is the applied shear load which is computed as horizontal force per unit length from the maximum shearing stresses obtained from finite element analysis.

$V_{\mathrm{rd}}=\frac{\left(f_{v k} t l\right)}{\gamma_{M}}$

The FEDRA seismic calculation is based on equivalent static loads at the level of each floor according to Eurocode 8 (2005) (EN 1998-1-1:2005), whereby the distribution of seismic forces by the height of the building is given in the form of a reversed triangular distribution.

\section{CHOICE OF CALCULATION MODELS FOR ANALYSIS 5.1 Input Parameters for Analysis}

A series of input data was prepared for the planned calculations in the analysis of the observed residential buildings. Data on physical - mechanical properties of embedded materials were determined experimentally. Data from laboratory tests from 2001, performed within the Laboratory for Construction Materials at the Faculty of Civil Engineering and Architecture in Nis, were used. The laboratory examined the class of masonry bricks for the needs of the planned refurbishment of the buildings listed here. Compression tests on specimens 250/120/65 mm $(1 / \mathrm{w} / \mathrm{h})$ were performed according to the national standards JUS B.D1.011:1987 Solid clay bricks - Technical requirements [21] and JUS B.D8.011:1987 - Methods of testing bricks, blocks and slabs [22]. The results obtained by laboratory testing are shown in Tab. 3 .

Table 3 Compressive strength testing and determination of brick class

Table 3 Compressive strength testing and determination of brick class
\begin{tabular}{|c|c|c|c|}
\hline & Failure load / N & Gross area / $\mathrm{mm}^{2}$ & $\begin{array}{c}\text { Compressive Strength / } \\
\text { N/mm }\end{array}$ \\
\hline 1 & 405000,00 & 30000,00 & 13,50 \\
\hline 2 & 320000,00 & 30000,00 & 10,67 \\
\hline 3 & 305000,00 & 30000,00 & 10,17 \\
\hline 4 & 360000,00 & 30000,00 & 12,00 \\
\hline 5 & 325000,00 & 30000,00 & 10,83 \\
\hline
\end{tabular}

Thus, it was found that the average compressive strength of the blocks was $11,43 \mathrm{~N} / \mathrm{mm}^{2}$, and the individual minimal compressive strength $10,17 \mathrm{~N} / \mathrm{mm}^{2}$. This means that the compressive strength of solid brick corresponds to class M10. The compressive strength of built-in mortars to classes M1 and M2.5, the concrete class corresponds approximately to class $\mathrm{C} 16 / 20$, and the embedded steel corresponds to type S220. The loads are the other essential inputs to carry out the analytical calculation under the FEDRA software package.

Starting from the basic analysis of the share of the surface area of structural walls and height of the building, according to EN 1998-1 for "simple masonry buildings", it can be concluded that, despite the sufficient contents of load-bearing walls, as shown in Tab. 2, buildings constructed with ordinary masonry walls are not allowed in seismic areas having the ground acceleration $a_{\mathrm{g}}=0,2 \mathrm{~g}$ (Tab. 4). At the very beginning of the examination of the existing buildings, their geometry, the shape of the floor plan and the height of the building, the first conclusion can be drawn about the recommended number of floors based on the provisions of EN 1998-1:2004. Masonry buildings with unreinforced walls are not allowed in the seismic intensity zone VIII. Therefore, the observed masonry buildings "type A" and "type B" consisting of $G_{\mathrm{r}}+3$ and B $+G_{\mathrm{r}}+3$ must be strengthened in the prescribed manner and adapted to the appropriate type of construction prescribed by EN 1998-1:2004 (Tab. 4). As emphasized in the introduction, this is only an approximate and a rough analysis.

The recommendation regarding the shape of the building floor plan layout is defined as approximately rectangular, with a required ratio of shorter and longer sides equal to or greater than 0,25 . In both cases, this condition is fulfilled ("type A" is 0,37 and "type B" is 0,96).

Designing the structure, that is, the formation of various variant solutions of the strengthened structure that served as a basis for the comparative analysis and drawing conclusions, was performed according to EN 1998-1:2004 (Tab. 4). "Simple masonry buildings" regulations apply only to buildings that meet these requirements and are not calculated. If the prescribed requirements for "simple masonry buildings" are unfulfilled, then they should be calculated.

Table 4 Recommended allowable number of storeys above ground and minimum area of shear walls for "simple masonry buildings"[1]

\begin{tabular}{|c|c|c|c|c|c|}
\hline \multicolumn{2}{|c|}{ Design ground acceleration at site $a_{g} S$} & $\leq 0,06 \mathrm{~g}$ & $\leq 0,09 \mathrm{~g}$ & $\leq 0,12 \mathrm{~g}$ & $\leq 0,20 \mathrm{~g}$ \\
\hline Type of masonry & Number of Storeys & \multicolumn{4}{|c|}{$\begin{array}{c}\text { Minimum sum of cross sections of horizontal shear walls in any one sdirection, as percentage } \\
\text { of the total floor area*) }\end{array}$} \\
\hline $\begin{array}{l}\text { Unreinforced masonry with } \\
f_{b} \geq 12 \mathrm{MPa}\left(f_{b} \geq 4 \mathrm{MPa}\right)\end{array}$ & $\begin{array}{l}1 \\
2 \\
3 \\
4\end{array}$ & $\begin{array}{c}2,0 \%(2,0 \%) \\
2,0 \%(3,0 \%) \\
3,0 \%(4,5 \%) \\
5,0 \%(\mathrm{n} / \mathrm{a})\end{array}$ & $\begin{array}{c}2,0 \%(3,0 \%) \\
2,5 \%(4,5 \%) \\
5,0 \%(\mathrm{n} / \mathrm{a}) \\
(\mathrm{n} / \mathrm{a})\end{array}$ & $\begin{array}{c}3,5 \%(5,5 \%) \\
(\mathrm{n} / \mathrm{a}) \\
(\mathrm{n} / \mathrm{a})\end{array}$ & $\begin{array}{c}6,0 \%(\mathrm{n} / \mathrm{a}) \\
(\mathrm{n} / \mathrm{a}) \\
(\mathrm{n} / \mathrm{a}) \\
(\mathrm{n} / \mathrm{a})\end{array}$ \\
\hline $\begin{array}{c}\text { Confined masonry } f_{b} \geq 4 \\
\mathrm{MPa}\end{array}$ & $\begin{array}{l}2 \\
3 \\
4 \\
5\end{array}$ & $\begin{array}{l}2,0 \% \\
2,0 \% \\
4,0 \% \\
6,0 \%\end{array}$ & $\begin{array}{c}2,5 \% \\
3,0 \% \\
5,0 \% \\
\text { n/a }\end{array}$ & $\begin{array}{c}2,0 \% \\
4,0 \% \\
\mathrm{n} / \mathrm{a} \\
\mathrm{n} / \mathrm{a}\end{array}$ & $\begin{array}{c}3,5 \% \\
\mathrm{n} / \mathrm{a} \\
\mathrm{n} / \mathrm{a} \\
\mathrm{n} / \mathrm{a}\end{array}$ \\
\hline $\begin{array}{l}\text { Reinforcedd masonry } f_{b} \geq 4 \\
\qquad \mathrm{MPa}\end{array}$ & $\begin{array}{l}2 \\
3 \\
4 \\
5\end{array}$ & $\begin{array}{l}2,0 \% \\
2,0 \% \\
3,0 \% \\
4,0 \%\end{array}$ & $\begin{array}{l}2,0 \% \\
2,0 \% \\
4,0 \% \\
5,0 \%\end{array}$ & $\begin{array}{c}2,0 \% \\
3,0 \% \\
5,0 \% \\
\mathrm{n} / \mathrm{a}\end{array}$ & $\begin{array}{c}3,5 \% \\
5,0 \% \\
\mathrm{n} / \mathrm{a} \\
\mathrm{n} / \mathrm{a}\end{array}$ \\
\hline
\end{tabular}




\subsection{Review of the Strengthening Variants}

In order to consider the existing condition of the observed A and B masonry buildings and the comparative analysis of different variant solutions of structural strengthening, a selection of calculation models was performed, as stated in [23]. The formation of variant solutions of strengthening was performed according to EN 1998-1:2004 and EN 1998-3:2005.

Model 1 shows the original, existing condition of the structure with non-reinforced walls, without additional stiffening and reinforcement. It enables the assessment of the actual state of the structure and the possible development of damage during previous seismic actions, so it is the basis for comparison with other models, i.e. variant strengthening solutions.

Model 2 represents a structure strengthened by introducing vertical tie beams made of the entire height of the building at the points where load-bearing - shear walls meet and intersect, and whose function is to further stiffen and strengthen the existing structure (in Fig. 3). Model 2 was formed on the basis of the first requirement of $\mathrm{EN}$ 1998-1:2004 (Tab. 4) related to the given number of storeys of the building.

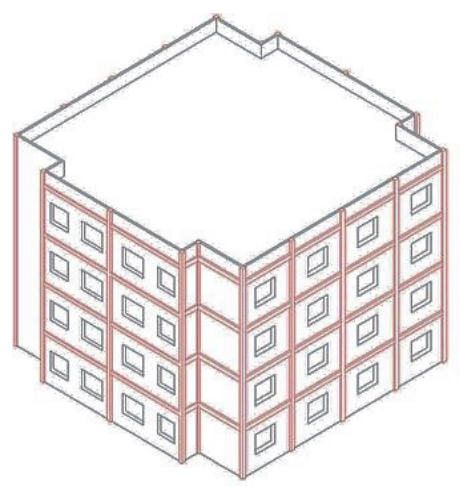

Figure 3 Strengthened and stiffened structure with vertical tie beamsModel 2 (building B)

Model 3 resulted from further analysis and instruction of EN 1998-1:2004, as another envisaged variant solution. It represents a strengthened construction with the introduction of reinforced masonry walls, where reinforced walls mean the installation of reinforcement in the horizontal joints of existing walls (in Fig. 4). The process of constructing reinforced masonry walls is quite demanding and long when it comes to existing buildings, so it is a serious drawback.

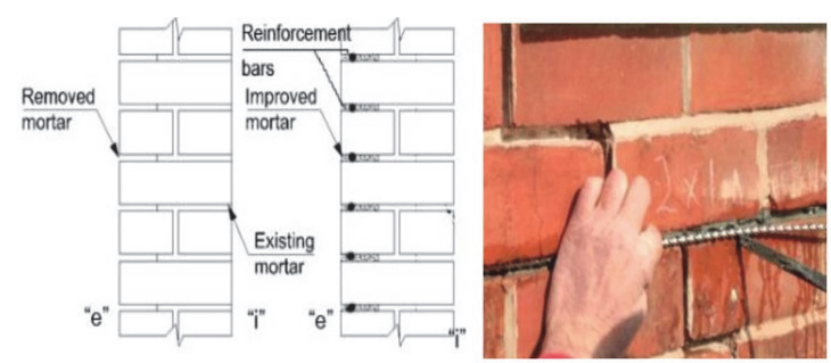

Figure 4 The installation of reinforcement bars in the horizontal joints of existing walls-Model 3

Model 4 is the most commonly used method of strengthening by applying reinforced concrete jacket on one side of the existing wall, usually the outside of the existing wall. Model 4 was formed according to the requirements of EN 1998-3:2005, which refers to the assessment of the condition and retrofitting of buildings. Reinforced concrete jackets are made on the pre-prepared surface of the existing walls by anchoring the wall with reinforcement mesh ø10/10 and then applying a layer of concrete C 25/30 $10 \mathrm{~cm}$ thick over it (Fig. 5). In this model, reinforced concrete jackets are provided on all bearing walls of the $x$ and $y$ directions and along the entire height of the buildings. Reinforced concrete jackets as vertical bearing elements, are interconnected by horizontal circulations and based on expanded and reinforced strip foundations.
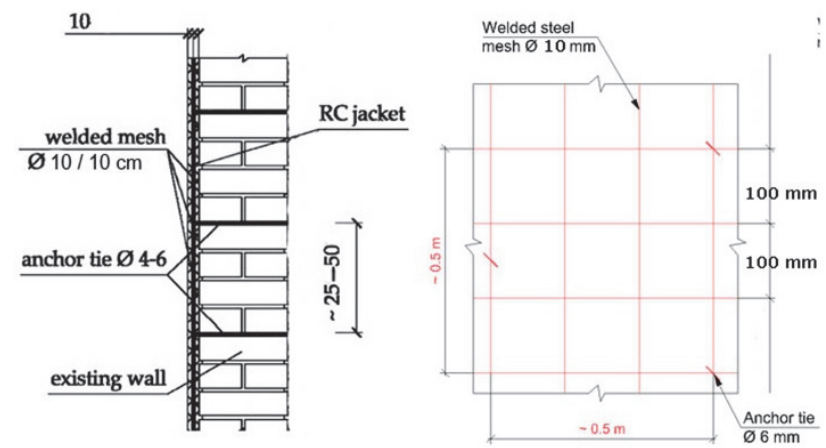

Figure 5 Strengthening structure by applying reinforced concrete jacket on one side of an existing wall-Model 4

When the comparative analyses of the results of Models 2, 3 and 4 showed that in some solutions there is a large increase in load capacity both for the compression and the shear loads, the question of the cost-effectiveness of these solutions arose. Then, Model 5 was built for additional analysis. Only the transverse walls of the ground floor (building B), ground floor and basement (building A) with the largest shear load-bearing capacity were strengthened with reinforced concrete jackets. In the case of the Model 5, all the load-bearing walls of the higher storeys are strengthened and stiffened by subsequently made vertical tie beams (in Fig. 6).
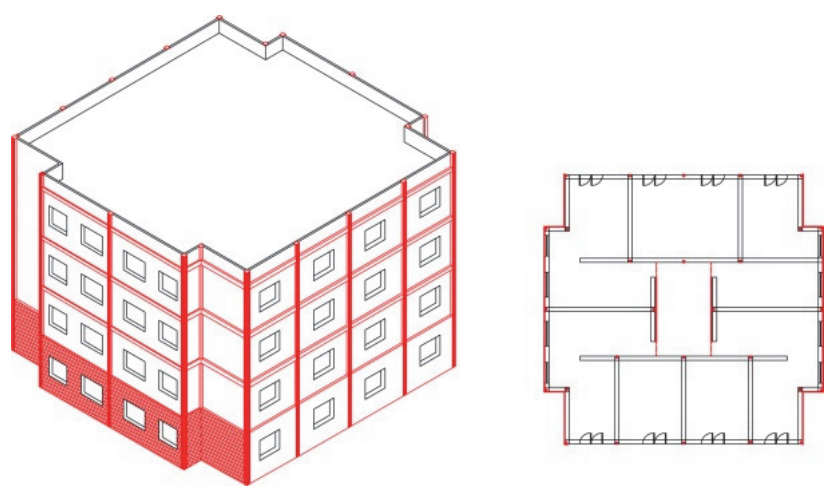

Figure 6 The transverse walls of the ground floor were strengthened with reinforced concrete jackets and the walls of higher storeys are stiffened by vertical tie beams-Model 5 (building B)

When choosing the strengthened variants, which are presented here in the calculation models, it was ensured that they primarily meet the requirements of EC 8, that they are technically and technologically suitable for construction and harmonized with the existing structure and its estimated condition. The cost-effectiveness 
(economy) of the applied solutions and the smallest possible impact on the normal functioning of possibly inhabited facilities during the execution of works were also taken into account.

\section{RESULTS OF THE CONDUCTED ANALYSIS}

The FEDRA software package, based on the criteria and rules of the latest European standards, enabled the modelling of the structure and the analytical verification of the bearing capacity of the masonry structure to the vertical and shear loads for the current state and three variant solutions of the structural reinforcement, which was the basis for comparative analysis and reaching conclusions [20]. With the input of actual material characteristics, geometry and load, checking the load-bearing capacity of the walls on the vertical load for the ground floor since it is the most unfavourable, showed that the design load capacity $N_{\mathrm{Rd}}$ is several times higher than the design value of the vertical load $N_{\mathrm{Sd}}$ for both observed buildings (Fig. 7). Such a result is expected given the considerable dimensions of the walls and the relatively small number of storeys.

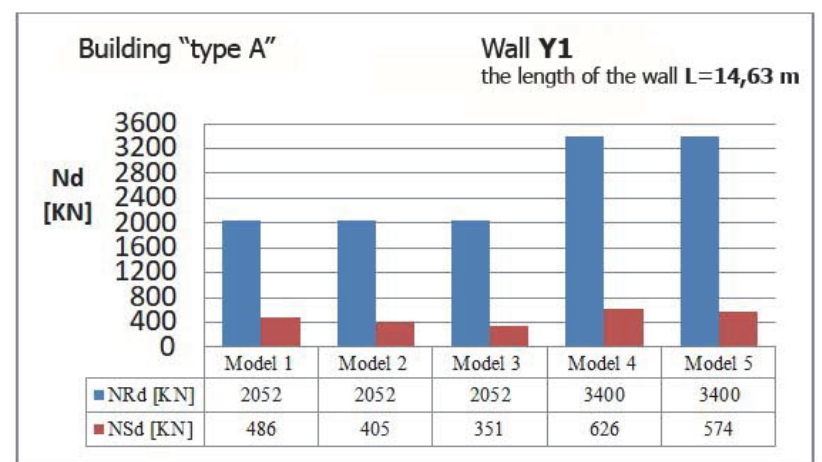

Figure 7 Comparative presentation of values of design bearing capacity $N_{R d}$ and vertical load $N_{\text {sd }}$ for the $Y 1$ wall
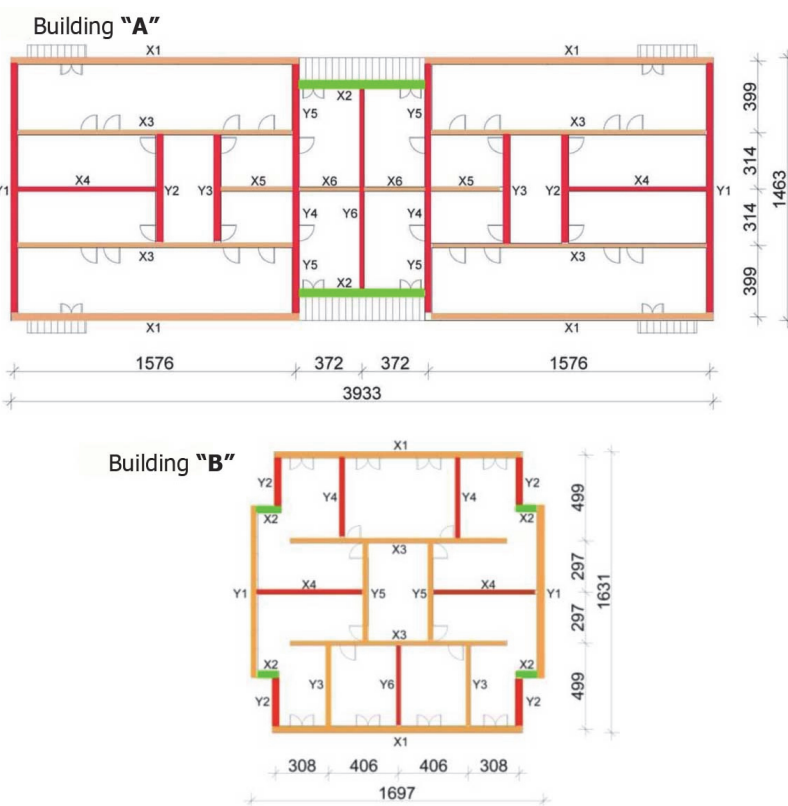

The shear load capacity excess $-\mathrm{V}_{\mathrm{Rd}}$ $100-200 \%=50-100 \%$

Figure 8 Presentation of exceeded shear strength of walls on the ground level of buildings $A$ and $B$
Considering the layout of the "type A" building (Fig. 1) and the representation of the shear walls (Tab. 2), as well as the design values of the load bearing capacity during the $V_{\mathrm{Rd}}$ shear and the design value of the shear load $V_{\text {Sd }}$ (in Fig. 8 ), it can be concluded that in Model 1A (current status) the shear strength of all walls is exceeded. For longitudinal, $x$ - direction walls, this exceeding is lower and ranges between $50-100 \%$, which means that the resistance the walls obtain to horizontal seismic forces is greater. For walls with a transverse, $y$ - direction, the shear strength capacity is exceeded by $100-200 \%$, because their number is almost half that of the $x$ - direction walls (in Fig. 8). Such a large exceedance of shear strength could cause damage to the walls in the form of diagonal cracks or cracks at a design ground acceleration of $0,2 \mathrm{~g}$.

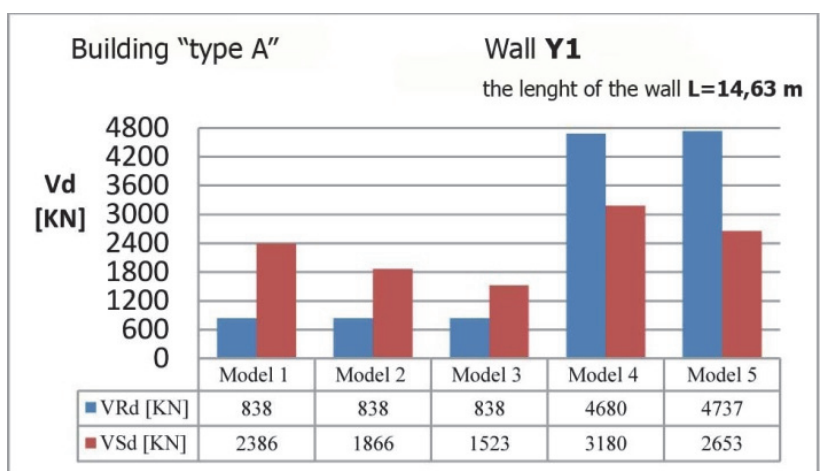

Figure 9 Comparative presentation of values of design bearing capacity $V_{R d}$ and shear load $V_{\text {sd }}$ for the $Y 1$ wall-building "type A"

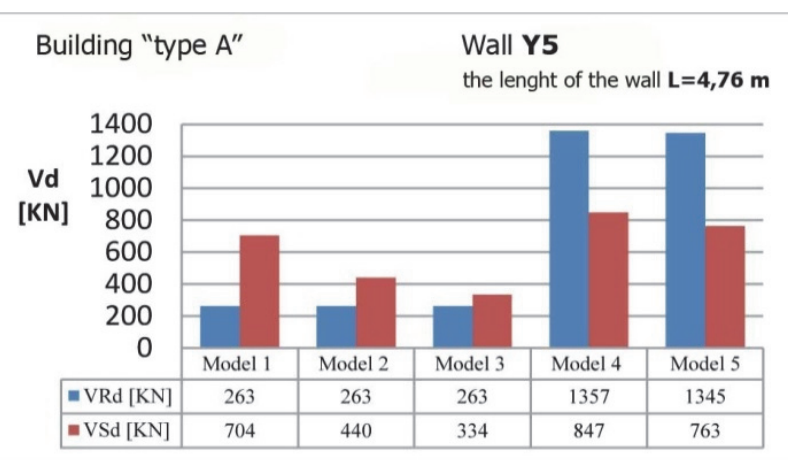

Figure 10 Comparative presentation of values of design bearing capacity $V_{R d}$ and shear load $V_{S d}$ for the $Y 5$ wall building "type $A^{\prime \prime}$

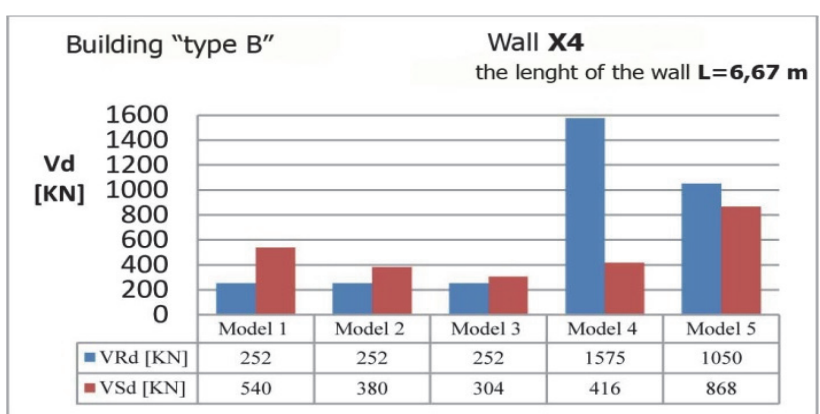

Figure 11 Comparative presentation of values of design bearing capacity $V_{R d}$ and shear load $V_{S d}$ for the X4 wall - building "type B"

The adopted strengthening of the building comprising introduction of vertical tie beams Model 2, is a system that connects and stiffens the walls, contributing to the compressive, flexural and shear load-bearing strength, both for loads in the plane of the walls and for loads perpendicular to their plane. The introduction of vertical tie 
beams at the points of contact, collision and, intersection of load-bearing walls the shear load capacity is still exceeded, but there is a $20-40 \%$ improvement over Model 1A (Fig. 9 and Fig. 10).

In the case of the "Type B" building, by introducing the vertical tie beams, the structure became even better strengthened and stiffened, the shear load decreased, but it is still slightly higher than the shear strength. In order to find solutions that will satisfy the wall shear load-bearing requirement to the greatest extent, Model 3, with reinforced masonry walls, was considered. After analysing the results obtained, for both types of structures, it can be concluded that the shear strength of the walls is still exceeded, but there is a noticeable improvement in both cases with respect to Model 1 by $35-53 \%$, as can be seen in Fig. 11 and Fig. 12.

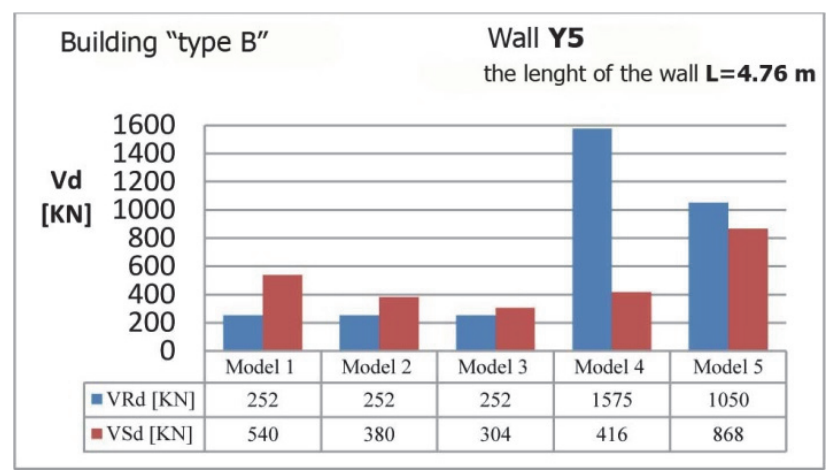

Figure 12 Comparative presentation of values of design bearing capacity $V_{R d}$ and shear load $V_{\text {sd }}$ for the $Y 5$ wall building "type B"

Using reinforced concrete jacketing on the exterior of the walls for strengthening, along the entire height of the building, in Models 4A and 4B, results in an extremely large increase in strength under both vertical and shear loads (Fig. 9, Fig. 10, Fig. 11 and Fig. 12). Experimental testing on the walls strengthened with reinforced concrete jackets, as Churilov [24] states, as well as some practical examples, showed that the main drawback of this method is the weak connection between the existing wall and the added concrete. Damage in the form of separation and bulging of concrete linings should be avoided by properly designing the linings, anchoring the linings to the existing wall, or interconnecting the linings on either side of the wall.

In the Models 4A and 4B the strength is not exceeded by vertical and shear loads, but the important question is the cost-effectiveness of this solution. Therefore, a logical conclusion of the preliminary analysis of the results is a proposal for the formation of another model of structural reinforcement, more cost-effective and satisfactory in terms of load-bearing capacity. Consequently, another model for analysis emerged, Model 5 (in Fig. 6), in which only the walls on the ground floor were reinforced exhibiting the highest exceeding of the shear strength. They were the transverse connecting walls to the greatest extent (Fig. 8). All the supporting walls of the higher storeys in this model are fixed and stiffened with consequently constructed vertical tie beams. This system of reinforcement of the existing masonry building shows the best results when the requirements and recommendations of Eurocode 8 - Part 3 and the costeffectiveness of the solution applied are compared. The load-bearing capacity to shear loads of the critical walls is not exceeded, as can be seen in Fig. 9, Fig. 10, Fig. 11 and Fig. 12.

\section{CONCLUSION}

In this paper, two characteristic types of existing masonry buildings, dating from the middle of the last century, were analyzed based on the finished standard designs. One has an elongated rectangular and the other almost a square base. The main drawbacks of their structural assemblies and geometrical characteristics are that the bearing walls are made without vertical tie ring beams and directed in one direction, making the buildings very sensitive to the effect of seismic forces from the opposite direction. In addition, it can be concluded that, despite the sufficient contents of load-bearing walls, as shown in Tab. 2, buildings constructed with ordinary masonry walls are not allowed in seismic areas having the ground acceleration $a_{\mathrm{g}}=0,2 \mathrm{~g}$.

The formation of various variant solutions for structural strengthening, that is, models for calculation, in accordance with the recommendations of Eurocode 6 and Eurocode 8, served as the basis of comparative analysis and making conclusions. Consequently, it was ensured that all solutions were efficient, easily applicable, economically viable and with the required degree of safety in seismic active areas.

Through the numerical calculation, the load bearing capacity of the walls for vertical and shear loading was verified within the FEDRA software package. The comparative analysis showed that Model 5, as one of the variant solutions of structural reinforcement, gave the best results. Subsequently constructed vertical tie beams further reinforced and stiffened the structure, and reinforced concrete jackets were made only on the lowest storeys, where the effect of the shear load is the greatest. Particular emphasis should be placed on the role of reinforced transverse, connecting walls in increasing the stiffness and load-bearing capacity of the structure, and thus in reducing the lateral displacements to which it would be exposed. In addition, the comparative analysis showed that more favourable results in all variant solutions of structural strengthening are achieved with buildings with a more uniform aspect ratio.

When considering the strengthening variants of the load-bearing structure of masonry buildings it was shown that comparative analysis has substantial importance in this process. It enables the assessment of the complete condition of the building structure and its behaviour in all variant solutions and all phases of seismic loading. The calculations and analyses conducted in this paper should contribute to the further development of current issues of their refurbishment in order to obtain safe and reliable facilities with the emphasis on the latest technical regulations, which define the area of seismic design of existing residential buildings.

\section{REFERENCES}

[1] Eurocode 8: Design of structures for earthquake resistancePart 1: General rules, seismic actions and rules for buildings. 2004, EN 1998-1:2004. EU, 231. 
[2] Eurocode 8: Design of structures for earthquake resistancePart 3: Assessment and retrofitting of buildings.2005, EN 1998-3:2005, EU. 89.

[3] ASCE, Prestandard and commentary for the seismic rehabilitation of buildings. 2000, FEMA 356, Washington, D.C.USA, 518.

[4] Beckmann, P. \& Bowles, R. (2004). Structural Aspects of Building Conservation. Elsevier Butterworth-Heinemann, 340, ISBN 0750657332

[5] Gattesco, N. (2011). New Materials for the Rehabilitation of Cultural Heritage. Czech Technical University in Prague, Faculty of Civil Engineering. Dottore in Ingegneria Civile. 3/5. Retrieved fromhttps://portal.cvut.cz/wpcontent/uploads/2017/04/HP2011-06-Gattesco.pdf

[6] Triantafillou, T. C. \& Fardis, M. N. (1997). Strengthening of historic masonry structures with composite materials. Journal Materials and Structures, 30, 486-496. https://doi.org/10.1007/BF02524777

[7] Ademović, N., Hrasnica, M., \& Oliveira, D. V. (2013). Pushover analysis and failure pattern of a typical masonry residential building in Bosnia and Herzegovina. Engineering Structures, 50, 13-29. https://doi.org/10.1016/j.engstruct.2012.11.031

[8] Churilov, S. \& Dumova-Jovanoska, E. (2009). Experimental and Analytical Research of Strengthening Techniques for Masonry. Proceedings on 3rd National Congress MuRiCo 3, Mechanics of masonry structures strengthened with composite materials, Venice, Italy, 8.

[9] Tomaževič, M. (2000). Seismic rehabilitation of existing masonry structures. Journal of the Croatian Association of Civil Engineers, Građevinar 52(11), 683-693.

[10] Tomaževič, M. (2014). Renewal of Existing Masonry Buildings in Seismic Regions: Experience and Rules. Journal of Association of Civil Engineers Geotechnical Engineers, Architects and Town Planners "Izgradnja", number 5-6, 193-208.

[11] Eurocode 6: Design of masonry structures - Part 1-1: General rules for reinforced and unreinforced masonry structures, SRPS EN 1996-1-1:2005, 125

[12] Technical Norms for Construction of High-rise Buildings in Seismic Areas, Official GazetteSFRJ, number 31, 1981. 52.

[13] Trogrlić, B. \& Harapin, A. (2008). Masonry Structuresabout design and calculation. Professional Development Program in Construction, University of Split, Faculty of Civil Engineering and Architecture, Split, 62.

[14] Ozmen, C., Akan A. E., \& Unay, A. I. (2011). Analysis of a historic masonry building. Journal of the Croatian Association of Civil Engineers, Građevinar, 63(5), 449-458.

[15] Stanišić, G. \& Kurtović-Folić. N. (2015). Methods for Determining the Potential for Revitalization of Architectural Heritage-Lessons of the City of Bern. Journal Materials and Constructions, 58(1), 25-57. https://doi.org/10.5937/grmk1501025S

[16] Kurtović-Folić, N. \& Folić, R. (1986). Old buildingsCharacteristic Damages and Their Patterns. Journal of the Croatian Association of Civil Engineers, Građevinar, 38(4), 153-168.

[17] Tomaževič, M. (1999). Earthquake-Resistant Design of Masonry Buildings. Series on Innovation in Structures and Construction, Imperial College Press, 1, 292. https://doi.org/10.1142/9781848160835_0002

[18] Rulebook on Temporary Technical Regulations for Construction in Seismic Areas, Official Gazette of SFRY, number 39, 1964.

[19] Penava, D., Radić, I., Gazić, G., \& Sigmund, V. (2011) Mechanical properties of masonry as required for the seismic resistance verification. Technical gazette, 18(2), 273-280.
[20] FEDRA Finite Element Analysis Programs, Masonry Buildings according to EC 6, Retrived from http://www.runet-software.com/FEDRA.htm

[21] JUS B.D1.011:1987: Massive clay bricks-Technical requirements. (Replaced with SRPS B.D1.011:2002)

[22] JUS B.D8.011:1987: Methods of testing bricks, blocks and slabs, 9. (Replaced with SRPS B.D8.011:2002)

[23] Savić, J. (2016). Revitalization of residential buildings in structural context. Doctoral dissertation, University of Niš, Faculty of Civil Engineering and Architecture,p.181, https://eteze.ni.ac.rs/application/showtheses?thesesId=503

[24] Churilov, S. (2012). Experimental and analytical research of strengthened masonry. Doctoral dissertation, University"Ss. Cyril and Methodius", Faculty of Civil Engineering, Skopje, 247.

\section{Contact information:}

Jelena SAVIĆ, PhD, Teaching/Research Assistant

(Corresponding author)

Faculty of Civil Engineering and Architecture, University of Niš

Aleksandra Medvedeva 14, 18000 Niš, Serbia

E-mail: jelena.savic@gaf.ni.ac.rs

Radomir FOLIĆ, Dr.Ing. Professor Emeritus

Dep of Civil Eng. And Geodesy,

Faculty of Technical Sciences, University of Novi Sad,

Trg D. Obradovića 6, 21000 Novi Sad

E-mail: folic@uns.ac.rs and r.folic@gmail.com

Dragan KOSTIĆ, PhD, Associate Professor

Faculty of Civil Engineering and Architecture, University of Niš, Aleksandra Medvedeva 14, 18000 Niš, Serbia

E-mail: dragan.kostic@gaf.ni.ac.rs

Veliborka BOGDANOVIĆ, PhD, Full Professor Faculty of Civil Engineering and Architecture, University of Niš, Aleksandra Medvedeva 14, 18000 Niš, Serbia

E-mail: veliborka.bogdanovic@gaf.ni.ac.rs

Miomir VASOV, PhD, Associate Professor

Faculty of Civil Engineering and Architecture, University of Niš, Aleksandra Medvedeva 14, 18000 Niš, Serbia

E-mail: miomir.vasov@gaf.ni.ac.rs 